\title{
Sistem Pakar Mengidentifikasi Minat Bakat Anak Dengan Metode Certainty Factor
}

\begin{abstract}
Rusmin Saragih
Address: STMIK Kaputama Binjai, Sumatera Utara - Indonesia

Email: evitha12014@gmail.com

*evitha12014@gmail.com

Abstrak

Banyak orang tua yang cendCrung memaksakan kehendaknya ketika memilih sekolah formal ataupun non formal untuk anaknya. Dikarenakan tidak mengetahui Minat dan bakat yang dimiliki oleh anaknya. Hal ini mengekibatkan anak akan sulit untuk berkembang. Dan sulitnya menemukan psikolog anak untuk berkonsultasi juga menjadi salah satu penyebab hal ini Sistem pakar mengidentifikasi minat bakat anak dibangun dengan bahasa pemrograman PHP dan database yang digunakan adalah Php MyAdmin (MySql). Sistem pakar harus mampu bekerja dalam kondisi ketidakpastian. Dalam menghadapi masalah, sering ditemukan jawaban yang tidak memiliki kepastian. Tinggi rendahnya tingkat ketidakpastian hasil identifikasi dipengaruhi oleh aturan yang tidak pasti dan jawaban pengguna. MetodeCertainty Factor yang merupakan suatu teori matematika untukmengakomodasi ketidakpastian pemikiran seorang pakar, guna mengggambarkan tingkat keyakinan pakar terhadap masalah yang sedang di hadapi.Hasil perhitungan diperoleh dari karakteristik yang ada, sehinggamenghasilkan identifikasi kecerdasan yang dimiliki oleh anak yaitu pada kecerdasan visual-spasial yang memiliki nilai kepastian paling kuat sebesar 99,60\%
\end{abstract}

Keywords - Minat, Bakat, Sistem Pakar, Certainty Factor

\section{Latar Belakang}

Setiap anak dilahirkan dengan bakat yang berbeda antara satu dengan yang lainnya. Identifikasi bakat anak merupakan hal yang sangat penting dilakukan. Hal ini dikarenakan setiap anak memerlukan program pendidikan yang sesuai dengan bakat mereka masing-masing, sehingga dapat mengembangkan dan menggunakan bakat mereka secara maksimal. Disinilah peran orang tua untuk terlebih dahulu mengenal bakat anak dari kecil, kemudian mengarahkan dan mengembangkannya. Tujuan sekolah yang mendasar adalah mengembangkan bakat dan minat peserta didiknya sesuai dengan jenjang pendidikannya. Guru sebagai orang tua kedua bagi anak didiknya disekolah yang memiliki peran penting dalam pengembangan kemampuan anak didiknya.

Sekolah Bilingual Nasional Plus Permata Bangsa Binjai merupakan salah satu lembaga pendidikan berstandar nasional yang menggunakan dua bahasa, yaitu bahasa inggris dan bahasa indonesia. Untuk menciptakan sumber daya manusia yang berkualitas pihak sekolah selalu berusaha untuk memberikan yang terbaik dengan mempersiapkan segala sesuatu yang dibutuhkan untuk kegiatan belajar mengajar. Selama ini Sekolah Bilingual Nasional Plus Permata Bangsa Binjai melakukan evaluasi secara manual dan hanya untuk menentukan kecerdasan, belum sampai pada tingkat menentukan minat dan bakat anak. Sistem yang masih manual dirasa kurang efektif dan efisien dalam segi biaya dan waktu. Sehingga penulis memberikan satu solusi dengan melakuakan penelitian untuk memudahkan guru dalam menerapkan metode belajar yang tepat bagi siswa agar sesuai dengan minat dan bakat yang dimiliki.

Penelitian yang dilakukan oleh [1], berjudul Analisa Bakat Anak Melalui Penerapan Sistem Pakar Dengan Metode Forward Chaining, yang menyatakan bahwa : "Mengenai permasalahan bakat anak, psikolog anak adalah salah satu tempat para orang tua untuk berkonsultasi tentang bakat yang dimiliki oleh anaknya. Namun, jumlah psikolog anak yang terbatas serta biaya konsultasi yang tidak murah membuat para orang tua mengurungkan niat untuk berkonsultasi. Pada akhirnya orang tua hanya menerka-nerka bakat anak, bahkan memaksakan kemampuan yang 
diinginkan oleh orang tua. Keinginan orang tua yang bertolak belakang dengan bakat alami yang dimiliki anak dapat menghambat prestasi anak. Untuk itu diperlukan analisa bakat anak agar dapat diketahui bakat dan minat anak sehingga anak dapat berkembang sesuai dengan keinginannya. Akar masalah dari penelitian ini adalah banyaknya bakat anak yang tidak tersalurkan dengan baik. Hal ini dikarenakan kurangnya pengetahuan para orang tua dalam menangani permasalahan bakat yang dimiliki anaknya, serta kurangnya pakar dalam mengatasi solusi terbaik dari permasalahan tersebut. Untuk itu diperlukan analisa terhadap bakat yang dimiliki anak". Berdasarkan uraian diatas, maka topik yang diajukan untuk penulisan skripsi berjudul "sistem pakar mengidentifikasi minat bakat anak dengan metode certainty factor (studi kasus : sekolah bilingual nasional plus permata bangsa binjai)".

\section{Metode}

\subsection{Pengertian Sistem Pakar}

Menurut [2] sistem pakar adalah suatu sistem yang dirancang untuk dapat menirukan keahlian seorang pakar dalam menjawab petanyaan dan memecahkan masalah. Sistem pakar akan memberikan pemecahan suatu masalah yang didapat dari dialog dengan pengguna. Dengan bantuan sistem pakar seseorang yang bukan pakar/ahli dapat menjawab pertanyaan, menyelesaikan masalah serta mengambil keputusan yang biasanya dilakukan oleh seorang pakar [3-9].

\subsection{Pengertian Minat dan Bakat}

Menurut [10] minat merupakan ketertarikan akan sesuatu objek yang berasal dari hati, bukan karena paksaan dari orang lain.Dalam Kamus Besar Bahasa Indonesia (KBBI), Minat berarti kecenderungan hati yang tinggi terhadap sesuatu, diartikan pula sebagai gairah keinginan. Dalam bahasa Inggris, minat sering digambarkan dengan kata-kata "Interest" atau "Passion". "Interest" bermakna suatu perasaaan ingin memperlihatkan dan penasaran akan suatu hal, sedangkan "Passion" sama maknanya dengan gairah atau suatu perasaan yang kuat atau antusiasme terhadap sesuatu objek [11-15].

\subsection{Pengertian Certainty Factor}

Menurut [16] Teori Certainty Factor (CF) diusulkan oleh Shortliffe dan Buchanan pada 1975 untuk mengakomodasi ketidakpastian pemikirian (inexact reasoning) seorang pakar. Seorang pakar, (misalnya dokter) sering kali menganalisis informasi yang ada dengan ungkapan seperti "mungkin", "kemungkinan besar", "hampir pasti". Untuk mengakomodasi hal ini kita menggunakan certainty factor (CF) guna menggambarkan tingkat keyakinan pakar terhadap masalah yang sedang di hadapi.

Menurut kusrini bentuk dasar rumus Certainty factor sebuah aturan jika $\mathrm{E}$ maka $\mathrm{H}$ ditunjukan oleh rumus dibawah ini (Mukafi, 2018):

$\mathrm{CF}[\mathrm{H}, \mathrm{e}]=\mathrm{CF}[\mathrm{E}, \mathrm{e}] * \mathrm{CF}[\mathrm{H}, \mathrm{E}]$

Keterangan :

1. $\mathrm{CFs}[\mathrm{E}, \mathrm{e}]$ : Certainty Factor evidence $\mathrm{E}$ yang dipengaruhi oleh evidence e.

2. $\mathrm{MB}[\mathrm{H}, \mathrm{E}]$ : Certainty factor hipotesis dengan asumsi evidence diketahui dangan pasti yaitu ketika $\mathrm{CF}(\mathrm{E}, \mathrm{e})=1$.

3. $\mathrm{MD}[\mathrm{h}, \mathrm{e}]$ : Certainty factor hipotesis yang dipengaruhi oleh evidence e.

Certainty factor merupakan CF akhir dari sebuah calon konklusi. CF ini dipengaruhi oleh semua CF paralel dari aturan yang menghasilkan konklusi tersebut. Certainty factor gabungan diperlukan jika suatu konklusi diperoleh dari beberapa aturan sekaligus. Berikut ini merupakan rumusan perhitungan untuk certainty factor gabungan :

$$
C F(C F 1, C F 2)= \begin{cases}C F 1+C F 2(1-C F 1) & \text { if } C F 1>0 \text { dan } C F 2>0 \\ \frac{C F 1+C F 2}{(1-[|C F 1|,|C F 2|])}, & \text { if } C F 1<0 \text { or } C F 2<0 \\ C F 1+C F 2(1+C F 1) & \text { if } C F 1<0 \text { dan } C F 2<0\end{cases}
$$

Untuk mendapatkan keyakinan dapat dengan cara mewawancarai seorang pakar dengan aturan CF(Rule). Sedangkan untuk menentukan nilai tingkat keyakinan dari user juga dapat menggunakan aturan yang sama. Nilai CF(Rule) dapat di interpretasi dengan "term" dari pakar, yang diubah menjadi nilai tertentu sesuai table berikut :

Tabel 1. Interprestasi Nilai CF

\begin{tabular}{ll} 
Uncertain Term & CF \\
Definitely not (pasti tidak) & -1.0 \\
Almost certainly not (hampir pasti tidak) & -0.8 \\
Probably not (kemungkinan besar tidak) & -0.6 \\
Maybe not (mungkin tidak) & -0.4 \\
Unknown (tidak tahu) & -0.2 to 0.2 \\
Maybe (kemungkinan) & 0.4 \\
Probably (kemungkinan besar) & 0.6 \\
Almost certainly (hampir pasti) & 0.8 \\
Definitely (pasti) & 1.0 \\
\hline
\end{tabular}

Metodologi penelitian ini dilakukan untuk mencari sesuatu secara sistematis dengan menggunakan metode ilmiah serta sumber yang berlaku. Dengan adanya proses ini dapat memberikan hasil penelitian yang baik dan tepat. Atas dasar metodologi penelitian yang digunakan, dapat dibuat suatu alur kegiatan seperti gambar 1 sebagai berikut: 


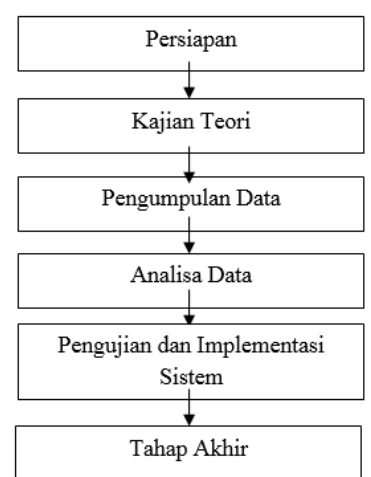

Gambar 1. Alur Kerja Penelitian

\section{Hasil}

\subsection{Analisis Sistem}

Berdasarkan identifikasi masalah dapat disimpulkan bahwa prinsip kerja pada sistem pakar untuk mengidentifikasi minat bakat anak adalah sebagai berikut:
a. Membuat basis pengetahuan yang mampu menampung data ciri-ciri yang dimiliki anak.
b. Membangun basis pengetahuan untuk menganalisa suatu masalah tertentu dan selanjutnya akan mencari minat bakat yang dimiliki oleh anak.
c. Merancang antar muka pemakai yang dapat menjangkau semua kebutuhan pengguna tanpa mempersulit user dalam penggunaan sistem.

\subsection{Perancangan Sistem}

Dalam merancang suatu sistem pakar identifikasi minat bakat anak penulis menggunakan metode certainty factor untuk menyelesaikan masalah, sistem identifikasi yang dirancang yaitu menyesuaikan ciri-ciri yang dimiliki anak dengan kesimpulan data yang didapat dan dikumpulkan ke dalam database, Adapun rancangan flowchart seperti gambar berikut :

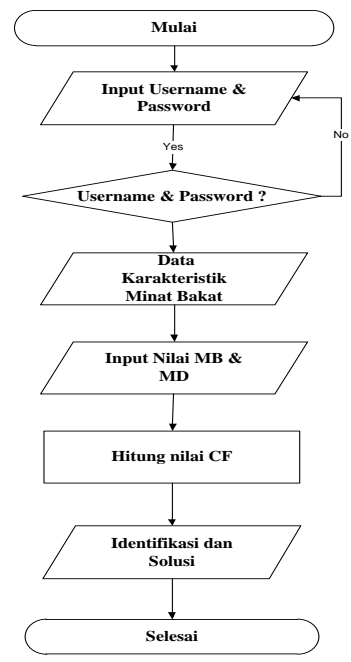

Program Studi Teknik Informatika

Universitas Prima Indonesia (UNPRI) Medan
Gambar 2. Flowchart Mengidentifikasi Minat Bakat Anak 3.3 Rancangan Use Case Diagram

Selanjutnya untuk memahami bagaimana sistem yang nantinya akan dibangun dapat dilihat proses sistem secara garis besar melalui unified modeling langguage(UML) seperti diagram use case berikut ini.

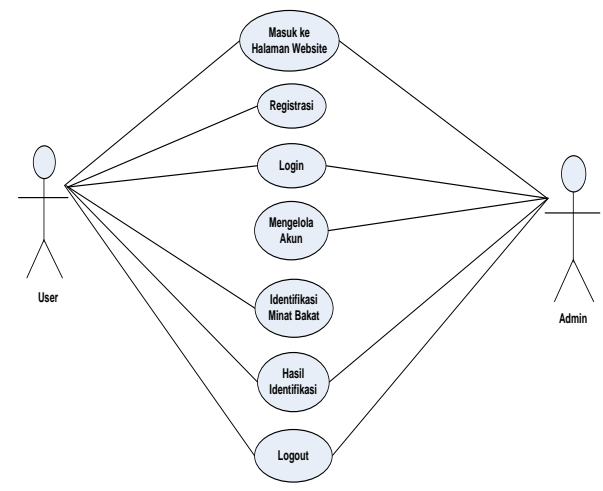

Gambar 3. Usecase Diagram Mengidentifikasi Minat Bakat Anak

Berdasarkan hasil analisa dan perancangan yang telah dicapai maka dapat diterapkan aplikasi sistem pakar identifikasi minat bakat anak berbasis Web, dimana dalam aplikasi ini pengguna dapat masuk dan kemudian menggunakan halaman website untuk mengetahui kecerdasan yang dimiliki oleh anak serta bisa mengetahui stimulasi yang tepat untuk membantu mengoptimalkan kecredasan yang dimiliki anak tanpa harus menemui seorang ahli (pakar) psikolog.

\subsection{Manual Program}

Berikut ini adalah tampilan hasil dari perancangan sistem pakar mengidentifikasi minat bakat anak. Berikut keterangannya :

a) Menu Utama

Berikut ini desain tampilan interface menu utama pengguna

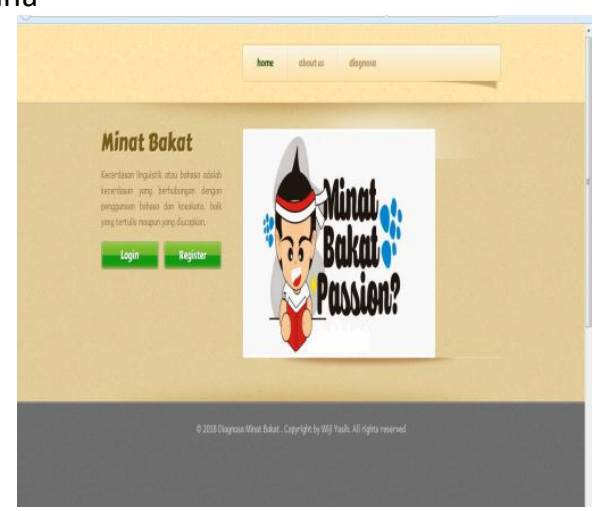

Gambar 4. Halaman menu utama

b) Halaman Login 
Berikut adalah desain tampilan interface login sistem.

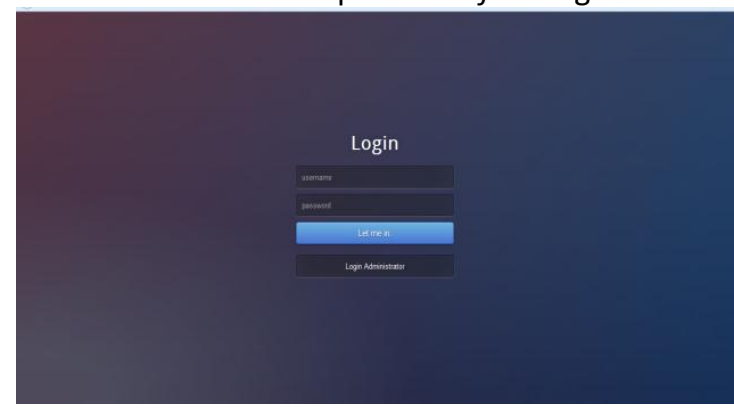

Gambar 5. Halaman login sistem

c) Halaman Registrasi

Berikut adalah desain tampilan interface halaman registrasi.

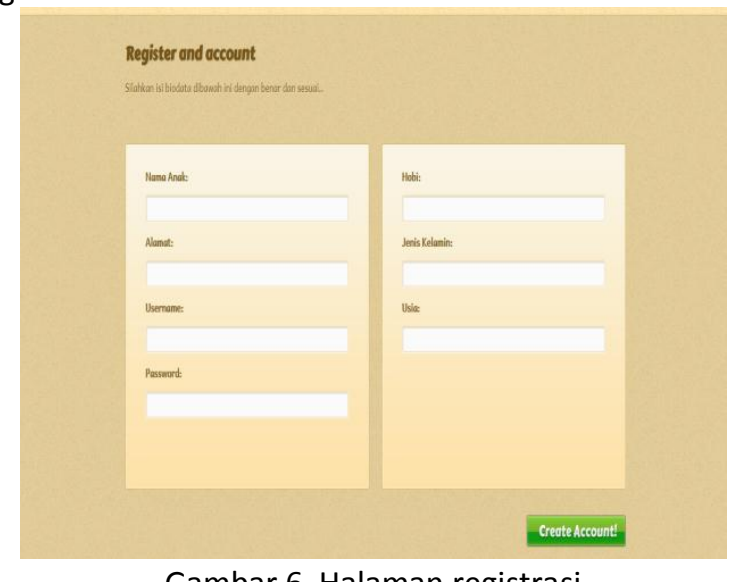

Gambar 6 Halaman registrasi

\section{d) Form konsultasi}

Halaman ini merupakan untuk mengidentifikasi minat bakat anak pengguna atau user melalui konsultasi yang ada pada diri pengguna atau user. Berdasarkan dari pertanyaan minat bakat anak yang diberikan yang kemudian akan dipilih oleh pengguna atau user.

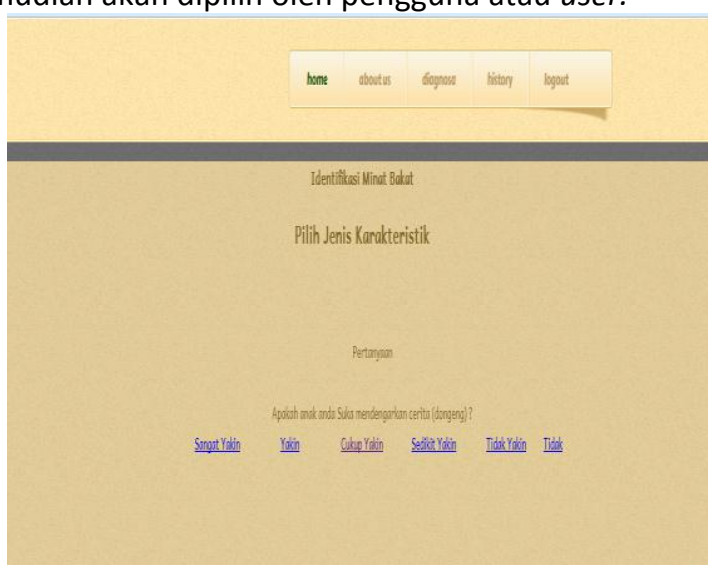

Gambar 7. Form konsultasi

e) Form Basis Pengetahuan
Halaman ini kemudian akan muncul ketika pengguna atau user selesai menjawab pertanyaan yang telah diberikan. Pengguna atau user akan mengetahui hasil dari konsultasi yang telah dilakukan.

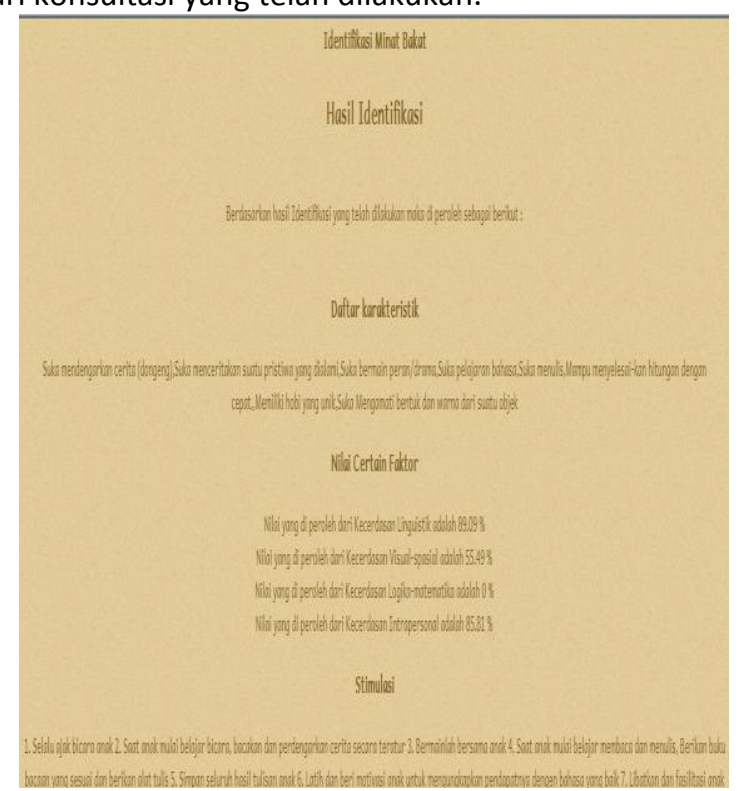

Gambar 8. Form Basis Pengetahuan

\section{f) Form Report Konsultasi}

Halaman ini selanjutnya akan tampil apabila pengguna atau user telah melakukan selesai dan ingin membuat report dari hasil konsultasi ya telah dilakukan.
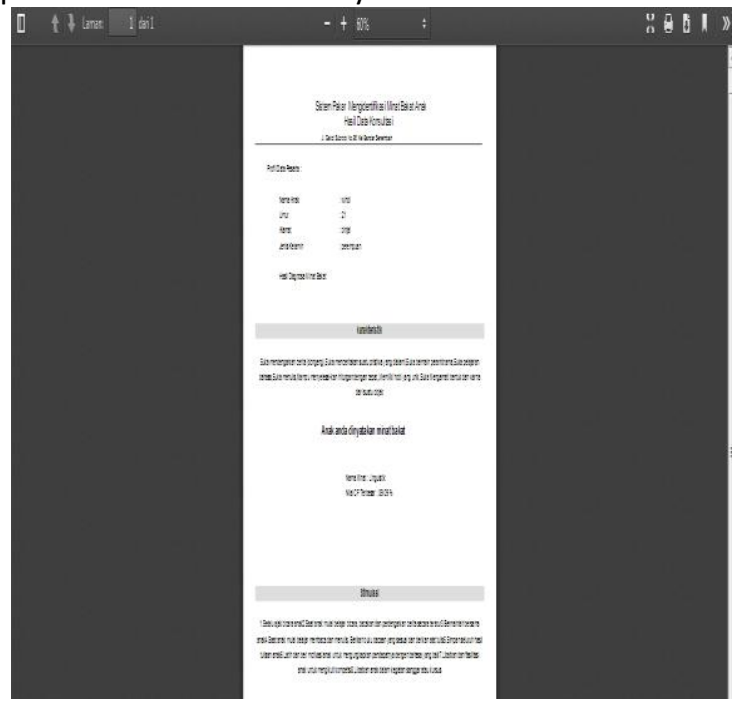

Gambar 9. Form Report Konsultasi

\section{Kesimpulan}

Berdasarkan hasil analisa yang telah dilakukan oleh penulis maka dapat ditarik kesimpulan sebagai berikut :

a. Dengan dibangunnya sistem pakar ini sebagai alat bantu dalam menentukan minat bakat anak di 
sekolah Billingual Nasional Plus Permata Bangsa menggunakan metode Certainty Factor berbasis web berdasarkan karakteristik yang dialami oleh pengguna atau user.

b. Dengan dibangunnya sistem ini dapat mengurangi biaya konsultasi dari segi waktu maupun biaya untuk mendapatkan informasi dan penanganan yang tepat tentang minat bakat pada anak.

c. Dengan diterapkannya sistem pakar identifikasiminat bakat pada anak berbasis web ini akan sangat membantu masyarakat umum untuk dapat berkonsultasi tentang minat bakat anak tanpa harus menemui psikolog serta akses yang dapat dijangkau kapanpun dan dimanapun pengguna atau user berada.

\section{References}

[1] Anhar. 2010. Panduan Menguasai PHP \& MySQL Secara Otodidak. MediaKita, Jakarta.

[2] Buaton, Relita. 2013. Mudahnya Membuat Website. Andi, Yogyakarta.

[3] Jogianto. 2005. Analisis dan Desain. Andi, Yogyakarta.

[4] Kusrini, 2006. Sistem Pakar Teori dan Aplikasi. Andi, Yogyakarta.

[5] Kusumadewi, Sri. 2003. Artificial Intelegence.Graha Ilmu, Yogyakarta.

[6] Laksana, Tri Ginanjar, dkk. 2016. Analisa Bakat Anak Melalui Penerapan Sistem Pakar Dengan Metode Forward Chaining, Cirebon:Prosiding Seminar Nasional.
[7] Lestari, Surip Anita, dan Handayani Rani Irma. 2017. Sistem Pakar Untuk Menentukan Bakat Anak Berdasarkan Kepribadian Menggunakan Model Forward Chaining. Jakarta:BINA INSANI ICT JOURNAL.

[8] Mukafi, Muhamad Hamdan. 2018. Pengembangan Sistem Diagnosa Awal Gangguan Kesehatan pada Ayam Potong Menggunakan Metode Certainty Factor. Malang : Politeknik Negeri Malang.

[9] Oetomo, Budi Sutejo Dharma. 2006. Perencanaan dan Pembangunan Sistem Informasi. Andi, Yogyakarta.

[10] Sefrina, Andin. 2013. Deteksi Minat Bakat Anak. Media Pressindo, Yogyakarta.

[11] Setiawan, Nanda Surya, dkk. 2013. Sistem Pakar Untuk Mendiagnosis Kecerdasan Majemuk Menggunakan Metode Fuzzy Expert System. Surabaya : STIKOM Surabaya.

[12] Sugiarti,Yuni. 2012.Analisis \& Perancangan UML (Unified Modeling Language) Generated VB.6.Graha Ilmu, Yogyakarta.

[13] Sutojo,T,dkk. 2011. Kecerdasan Buatan.Penerbit Andi, Yogyakarta.

[14] Turban,Efraim, dkk. 2005.Decision Support Systems and Intelligent Systems. Andi, Yogyakarta.

[15] Yatini, Indra, B. 2010. Flowchart, Algoritma, dan Pemrograman Menggunakan Bahasa C++ Builder. Graha Ilmu, Yogyakarta.

[16] Yulianti, Wita. 2016. Aptitude Testing Berbasis Case-Based Reasoning Dalam Sistem Pakar Untuk Menentukan Minat Dan Bakat Siswa Sekolah Dasar. Pekan Baru : UNIVRAB. 